SOCIAL MEDIA, PARENTS AND INTERNALIZING PROBLEMS

Associations Between Young Adults' Social Media Addiction, Relationship Quality with Parents and Internalizing Problems: A Path Analysis Model

Date of initial submission: October 21, 2021

Date of $1^{\text {st }}$ resubmission: January 14, 2022

(C) 2022, Canadian Psychological Association. This paper is not the copy of record and may not exactly replicate the final, authoritative version of the article. Please do not copy or cite without authors' permission. The final article will be available, upon publication, via its DOI: $10.1037 / \mathrm{cbs} 0000326$ 


\begin{abstract}
The pervasiveness of social media in the lives of young adults raises concerns about the potential of problematic use. Social media addiction is likely to affect positive and negative aspects of the relationships quality with mothers and fathers but mechanisms explaining these associations remain unknown. Participants in this study $\left(N=435 ; M_{\mathrm{age}}=19.17 ; S D=0.30\right)$ completed the Bergen Social Media Addiction Scale and reported their symptoms of anxiety, depression and the quality of the relationship with mothers and fathers (i.e. conflict, satisfaction, equality). Considering important confounding variables, results of a path analysis model show that the level of social media addiction is related to high conflict, low satisfaction and low equality with father, and high conflict and low equality with mother. Moreover, social media addiction is positively linked to symptoms of anxiety and depression. Finally, anxiety and depression mediate the links between social media addiction and conflict, satisfaction and equality with the mother, and conflict and satisfaction with the father. Our findings contribute to the understanding of the potential mechanisms underlying the associations between social media addiction and the relationship with parents in young adults. Theoretical explanations and practical implications are proposed in discussion. Future research should use a longitudinal design to support this mediating effect.
\end{abstract}

Key words: Social Network Addiction; family relationship; anxiety; depression

Public significance of the study. Young adults with social media addiction symptoms are more likely to have poorer relationship quality with parents and to exhibit symptoms of anxiety and depression. The results of this study also suggest that internalizing problems potentially act as mechanisms that may explain part of the link between social media addiction and relationship quality with parents. 


\section{Associations Between Young Adults' Social Media Addiction, Relationship Quality with Parents and Internalizing Problems: A Path Analysis Model}

The terms "social media" (e.g. Facebook, Twitter, Instagram) refer to the set of Internet communication channels that facilitate the perception of visual and verbal interactions between users (Carr \& Hayes, 2015). These are an integral part of adolescents and young adult's lives today. According to a recent report by the Pew Research Center (2019), 90\% of Americans between the ages of 18 and 29 use at least one social media. Moreover, while youths spend about 1:10 of their day on social media, 63\% report using it "every day" (Rideout \& Robb, 2019).

The pervasiveness of social media raises questions about the potential of problematic use. But what distinguishes problematic use from non-problematic use? According to some authors, it is not necessarily how long, but rather how one uses social media that defines problematic use (Boer et al., 2021; Kuss \& Griffiths, 2017; Shensa et al., 2017). For some individuals, their social media behaviors are similar to those included in substance-related addictions (Andreassen et al., 2015). Kuss and Griffiths (2017) refer to social media addiction when individuals present six criteria of behavioral addiction (i.e. salience, mood modification, tolerance, withdrawal, conflict, relapse). For example, for these individuals, social media use becomes one of the most central activities in their lives (salience). When they are deprived, they may experience psychological and even physiological difficulties (withdrawal), which may lead them to reinstate these

problematic behaviours, sometimes even in an amplified way (relapse). Psychometric instruments to measure this potential addiction have emerged in recent years. Notably, the Bergen Social Media Addiction Scale allows to estimate users' level of addiction (Andreassen et al., 2012). This 6-item instrument is based on addiction criteria initially listed by Griffith (2005), and has been attested by several recent studies as theoretically valid (Andreassen, 2015; Andreassen et al., 
2016). Although the concept of social media addiction is not based on any defined clinical criteria, the literature suggests that some individuals display behaviors related to their use that can be best describe in terms of addiction (e.g., compulsive and uncontrollable behaviors; Andreassen et al., 2012; Andreassen, 2015). Thus, the term "addiction" is used because it has a clear theoretical basis (Andreassen, 2015).

Among the theoretical frameworks for the pathogenesis of social media addiction, the cyber-developmental framework (CDF) proposed by Stavropoulos et al. (2021) attempts to explain why some individuals use digital technologies in an adaptive way and others do not. At the individual level, this model proposes three interacting cyber-layers: 1) virtual presence, which consists of experiencing digital environments as the real world (a high level of presence generally results in a feeling of escape from the real world), 2) the online flow, which consists of the emotional engagement an individual has with virtual applications, notably observable through the consumption of attention and the accelerated perception of time it can provokes, and 3) the virtual self-presence, which consists of the way people present themselves online, sometimes different from reality. The more pronounced and maladjusted these aspects are, the more likely the use of social media is to be maladaptive. In addition, the CDF proposes several environmental cyber-systems inspired by the work of Bronfenbrenner and Morris (2007), including the microsystem, which consists of the effects of immediate contexts such as friends and family, and the macro-system, which represents the influence of the community (e.g., societal trends projected on social media). Thus, this model suggests that these personal and relational components may be more salient in some individuals and may interact with each other in a way that some become more vulnerable to exhibiting symptoms of social media addiction and experiencing related adjustment difficulties.

\section{Social Media Addiction and Quality of the Relationship with Parents}


Social media has completely transformed the way we interact with each other. While social interactions were completely offline in the past decades, a significant proportion of these interactions now take place online. This raises some concerns regarding the impact of these media on the quality of social relationships. Indeed, over-investment in online behaviors has the potential to lead to interpersonal relationship difficulties (Kilinç et al., 2019). Since the average level of social media use continues to increase worldwide (Pew Research Center, 2019), it is therefore crucial to investigate these links. It is especially important to examine the impact on the quality of the relationship with the parents. In young adulthood, a positive relationship with parents is linked to important developmental outcomes, including successful transition to adulthood and life satisfaction (Fingerman et al., 2012)

While the links between social media and the parent-child relationship has received little attention in young adulthood, some studies have investigated these links in adolescence. Sampasa-Kanyinga et al. (2020) conducted a cross-sectional study with 9,732 adolescents and observed poorer quality of the mother-daughter, father-daughter and father-son relationships in those who use social media more than two hours per day. However, this study does not take into account addiction to social media, whereas this could be harmful regardless of the time invested (Shensa et al., 2017). Moreover, the quality of the relationship with the mother and the relationship with the father were measured with only one item. Yet, personal relationships with parents are multidimensional and include both negative (e.g. conflict) and positive (e.g. equality and satisfaction) aspects. In a recent cross-sectional study with 583 adolescents, Bilgin et al. (2020) found that overall distress in the family, conflicts with the mother regarding school and the fact that the adolescent is in the middle of parental conflicts were linked with social media addiction. 
The results obtained in previous studies showed a link between social media use and negative aspects of the parent-adolescent relationship. However, young adulthood differs from adolescence in several ways, such as the exploration of identity, the instability of this developmental period, and the life opportunities that become completely different (Tanner \& Arnett, 2016). Several plausible hypotheses suggest that problematic social media use may also be link to the parent-child relationship at this age. First, some authors argue that the increasing normative need for autonomy occurring between adolescence and young adulthood can lead to conflicts with parents and bring young adults to fill their need for social support via the Internet or, for instance, social media (Boniel-Nissim \& Sasson, 2018). Second, it is possible that parents of young adults perceive excessive social media use as immature, since it is generally known that teenagers use social media more than adults (Schimmele et al., 2021). Thus, some parents might expect social media use to decrease with age. Young adults who abuse social media may therefore be less close to their parents since they would not meet parental expectations. Third, adolescence is characterized by a quest for independence from the parents accompagnied by an increased involvement in the peer group, whereas young adulthood generally includes the reinsertion of the importance of parents (Miller-Slough \& Dunsmore, 2016; Fingerman et al., 2012). It is therefore possible that young adults who present social media addiction may maintain this preference for peers due to the social networking nature of these platforms, which could then affect the relationship with parents. Similarly, other authors argue that the time spent interacting virtually with peers could simply substitute the need to interact offline with parents, thus potentially impacting the relationship with parents (Moawad \& Ebrahem, 2016). In sum, there is reasons to expect that the link between problematic social media use and negative aspect of the relationships with parents observed in adolescence also extent to young adulthood, but this remains to be tested. 


\section{Social Media Addiction and Internalizing Problems}

Recent systematic reviews and meta-analyses conclude that problematic use of social media is linked to poorer mental health among adolescents and young adults (Marino et al., 2018; Keles et al., 2020). More specifically, recent studies conducted with young adults identified links between problematic use of social media and anxiety and depression (Lin et al., 2016; Mamum \& Griffiths, 2019; Shensa et al., 2017; Shensa et al., 2018; Vannucci et al., 2017). Some authors argue that social comparison theory (Festinger, 1954) could explain these links. This theory suggests that humans have an innate tendency to compare themselves with others. Indeed, people who overuse social media may tend to compare themselves more with others and the volume of these comparisons is linked to psychological distress regardless of the direction of these comparisons (i.e., whether they are downward or upward comparisons; Steers et al., 2014). Also, social media use is known to be time consuming. It is therefore possible that the feeling of having wasted time in meaningless activity after using social media obsessively can lead to anxiety or depression (Lin et al., 2016). Additionally, the use of social media may contribute to the perception that young adults feel overloaded by communication from a variety of sources. This stressful component can make emotional distress more prone (Chen \& Lee, 2013). However, not all studies found association between problematic use of social media and anxiety and depression, and some studies do not support it (Berryman et al., 2018; Coyne et al., 2020). It is therefore necessary to examine different populations worldwide since these associations are not clear.

Several hypotheses allow us to believe that internalizing problems could act as mediator in the association between social media addiction and quality of the relationship with parents. Some studies have already shown that the relationship with parents is related to internalizing problems and these, in turn, are related to more online behaviors (Sela et al., 2020; Wang et al., 
2018). One possibility raised in these studies is that a poorer relationship with parents increases the risk of experiencing psychological distress and that one way to cope with this distress is to display compulsive online behaviors (Sela et al., 2020). However, no study has supported the direction of the link and none has examined the reverse association. Yet, several hypotheses suggest that internalizing problems may mediate the relationship between social media addiction and the relationship with parents in young adulthood. While it is well documented that the problematic use of social media strongly predicts the level of internalizing problems (Keles et al., 2020; Marino et al., 2018; Shensa et al., 2018), internalizing problems are also linked to the quality of the relationship with parents (Branje et al., 2010; Van Eijk et al., 2012; Yap et al., 2014). Those who present internalizing symptoms may tend to use self-protective strategies (e.g. avoidance behavior), which impairs their ability to maintain close relationships (Tillfors et al., 2012). This aspect could particularly affect the relationship with parents, especially during a stressful period such as the transition from adolescence to adulthood. It is also possible that young adults with addiction symptoms are more likely to share their distress with peers and romantic partners rather than parents, since they are important parts of young adult social lives and can possibly better understand their reality (Miller-Slough \& Dunsmore, 2016; Markiewicz et al., 2006). While the link between social media addiction and the quality of the relationship with parents may be bidirectional, it is possible that social media addiction could affect the relationship with parents in young adults partly because of the psychological distress that this problematic use can generate. To our knowledge, this is the first study to propose a mechanism by which this link could exist.

\section{The Present Study}

The first objective is to examine the link between social media addiction and the quality of the relationship with the parents in young adults. Three dimensions of the relationships 
(conflict, satisfaction and equality) with the mother and the father are investigated. The second objective is to add weight to the studies examining the link between social media addiction and internalizing problems (anxiety and depression) in young adults. The results of recent studies are contradictory and more data on the question is needed, especially in North America. The third objective is to investigate internalizing problems as a mechanism by which the link between social media addiction and quality of the relationship with parents may exist. Hypotheses are that: a) social media addiction is linked with poorer relationship quality with the mother and the father, b) social media addiction is linked with higher level of internalizing problems, and c) internalizing problems are a mediator in the association between social media addiction and the quality of the relationship with parents. Family income, gender and parental levels of education are also considered as these could be important confounding variables (Fingerman et al., 2012; Hair et al., 2008; Sampasa-Kanyinga et al., 2020).

\section{Method}

\section{Participants}

A total of 435 young adults $\left(62.6 \%\right.$ male; $\left.M_{\text {age }}=19.17 ; S D=0.30\right)$ participated in this study. The recruitment of participants was part of a broader project aimed at evaluating the effects of a prevention program for elementary school children (Poulin et al., 2013). A sample of 1038 children youths were initially recruited from 250 kindergarten classes in a Canadian city with a population of 500,000 . They then took part in a follow-up assessment at 19 years of age and the current study data were collected at that time. At the time of the age 19 data collection, $88,6 \%$ of the participants still live with at least one parent. The average annual household income before taxes was 97,000 CAD. A total of $19.5 \%$ of participants were no longer attending school at the time of data collection, $35.8 \%$ were finishing high school or were in a professional education program, and $44.7 \%$ were attending CEGEP (which is a pre-university program that 
precedes university in the province of Quebec). The majority of participants are of Canadian origin $(85.5 \%)$ and all speak French.

Comparison analyses were conducted to examine whether the participants in our sample $(n=435)$ differed from those who were initially recruited and did not participate in data collection at age $19(n=603)$. These analyses show that those who participated in the study at age 19 come from families with higher annual income $(t(915)=-4.37, p<.001, d=-.29)$ and parents with higher levels of education $(t(834=-2.67, p=.008, d=-.19 ; t(933)=-3.04, p=.002, d=-.20$; for father and mother, respectively).

\section{Procedures}

At age 19, questionnaires were completed privately by the participants at their home during a visit by trained research assistants. Gift certificates were given to the participants to thank them. This study was approved by the Institutional Review Board of the Universite du Québec à Montréal.

\section{Instruments}

\section{Social media addiction}

Young adults completed the Bergen Social Media Addiction Scale, which is an adaptation of the Bergen Facebook Addiction Scale (Andreassen, 2012), where the term "Facebook" is replaced by the terms "social media". It consists of 6 items (e.g. "in the last year, how often have you tried to reduce your use of social media, without success?") based on Griffith's (2005) six addiction criteria (i.e. salience, mood modification, tolerance, withdrawal, conflict, relapse), rated on a 5-point Likert scale ranging from $1=$ "very rarely" to $5=$ "very often". The total score is the mean of the results obtained for each item (current reliability: $\alpha=.8, \omega=.80$ ).

\section{Symptoms of anxiety and depression}


Participants completed the Mental Health and Social Inadaptation Assessment for Adolescents (Côté et al., 2017). This self-reported questionnaire is based on the symptoms listed in the Diagnostic and Statistical Manual of Mental Disorders (DSM-5) and allows to compute a score for anxiety (9 items; e.g. "in the last 12 months, I worried about my past behavior", current reliability : $\alpha=.80, \omega=80$ ) and depression ( 8 items; e.g. "in the last 12 months, I lost interest in things I usually like", current reliability: $\alpha=.82, \omega=.82$ ). Participants were asked to report on a 3 point Likert scale ("never true", "sometimes true", "always true") their level of anxiety and depression. The total scores are represented by the mean of the items of the subscale.

\section{Quality of the relationship with father/mother}

Participants reported three aspects of their relationship with the father and their relationship with the mother by completing items from the Network Relationships Inventory (Furman \& Buhrmester, 1985). Relationship satisfaction (3 items; e.g., "Are you satisfied with your relationship with your father/mother", current reliability: $\alpha=.90, \omega=.90$, for father and mother) and conflict (3 items; e.g. "how often are you and your father/mother angry with each other", current reliability: $\alpha=.83, \omega=.84$ for father and $\alpha=.85, \omega=.86$, for mother) were measured on a 5-point Likert scale, ranging from $1=$ "never" to $5=$ "always". An additional scale to measure equality in the relationship inspired by Adler and Furman (1988) was also completed by participants (3 items; e.g. "does your mother/father consider you as an adult? ", current reliability: $\alpha=.61, \omega=.66$ for father and $\alpha=.61, \omega=.65$ mother). The mean of the scores on the items for each subscale was calculated as the total score.

\section{Covariate}

Parents were asked to report total gross annual family income before taxes on a 13-point scale, ranging from "less than $\$ 9,999$ " to " $\$ 130,000$ and over". Furthermore, mothers and fathers were asked to report their level of education by stating the highest level of education completed 
on a 12-point scale ranging from secondary one (the equivalent of $7^{\text {th }}$ grade in the U.S. school system) to postdoctoral diploma. We have then substituted the level of education by the number of school years required to reach it, to facilitate comparison with the international school systems.

\section{Data analysis}

Path analyses were conducted using Mplus version 7.4 (Muthén and Muthén, 19982015). Figure 1 illustrates the tested model. Latent variable was created from the scores of anxiety and depression in order to attest internalizing problems. We conducted the analyses with the weighted least squares (WLS) estimator in order to address the moderate non-normality of certain variable distributions. For the examination of the indirect effects, we used a 5000 bootstrap resamples in order to have non-biased 95\% confidence intervals (Hayes, 2018). In addition, to examine the model fit, several fit indices were considered: the chi-square test of model fit (non-significant chi-square value indicate good fit), the root mean square error of approximation (RMSEA: $\leq .05$ represent good fit; Browne and Cudeck, 1992), the comparative fit index and the Tucker-Lewis index (CFI/TLI : $\geq .95$ represent good fit; Hu \& Bentler, 1999). Since the interaction between social media addiction and gender was not significant in any relationship ( $\beta$ ranging from -.28 and .15 , all $p \geq .13$ ), we include gender as a covariate in the analyses. Family income and parental levels of education were also included as covariates in these analyses.

\section{Results}

\section{Descriptive statistics}

Table 1 reports the descriptive statistics as well as the bivariate correlations between the variables under study. Examination of this table indicates that participants generally report moderate levels of social media addiction, anxiety and depression. In addition, social media 
addiction is significantly related to the level of anxiety, depression and all of the component of the relationship quality with both parents. These correlations are low to moderate. For the control variable, family income and mothers' level of education are not significantly correlated with the majority of the variables under study. Fathers' level of education is related to anxiety and depression, but this correlation is low. Finally, gender is significantly related to the level of anxiety, depression and social media addiction, suggesting that females present more symptoms than males.

\section{Result of Structural Equation Modeling}

The results of the path analyses are presented in Table 2 . The model fit the data well, $\left(\chi^{2}\right.$ $[22]=26.54, p=.23, \mathrm{CFI} / \mathrm{TLI}=.99 / .99, \mathrm{RMSEA}=.02(90 \% \mathrm{CI}=.00, .05)$. For the latent variable, both the anxiety and depression scores significantly contribute to the internalizing problem latent factor $(\beta=.85, \mathrm{SE}=.03,95 \% \mathrm{CI}[.79, .92] ; \beta=.88, \mathrm{SE}=.03,95 \% \mathrm{CI}[.81, .94]$; for anxiety and depression respectively). The model explain $25 \%$ of the variance in internalizing problems, and between $7 \%$ and $14 \%$ of the variance in the outcomes representing relationship quality with parents (conflit with mother being the highest). The upper part of Table 2 shows that, after controlling for family income, gender and parental education, social media addiction score significantly predicts the level of internalizing problems, conflict, satisfaction and equality with the father, and conflict and equality with the mother. No significant direct association is observed for the level of satisfaction with the mother.

The lower part of Table 2 shows the indirect effects of social media addiction and the relationship quality with parents, via internalizing problems. The results show that internalizing problems partially mediate the association between social media addiction and conflict and satisfaction with the father, as well as conflict and equality with the mother. Results show a full 
mediation for the satisfaction with the mother. Indeed, social media addiction predicts a high score of internalizing problems which, in turn, predicts a poorer quality of relationship with parents. No indirect effect was found for the equality with the father, but the $95 \%$ confidence interval shows that this association is very close to a significant value so this result must be interpreted with caution.

For the control variables, the results show that gender predicts the level of internalizing problems, $\beta=-.25, \mathrm{SE}=.05,95 \% \mathrm{CI}[-.34,-.16]$, as well as equality with the mother, $\beta=-.13$, $\mathrm{SE}=.05,95 \% \mathrm{CI}[-.25,-.05]$, indicating that females have more internalizing problems and more equality with their mothers than males. Also, a high father's education level predicts a high level of satisfaction with the latter, $\beta=.12, \mathrm{SE}=.05,95 \% \mathrm{CI}[.03, .21]$. The other covariates have no significant effect in our analyses.

\section{Discussion}

As reported by Andreassen et al. (2015), social media can likely lead to symptoms of addiction similar than substance-related addiction. To date, no study has examined simultaneously the links between social media addiction, anxiety, depression and the relationship quality with the father and the mother in young adults in order to have a more general picture of this phenomenon. As expected, social media addiction predicts the level of internalizing problems and several aspects of the relationship quality with parents. Moreover, we found that internalizing problems mediate most of these associations, which suggest that they act as a possible mechanism by which social media addiction is linked to the quality of the relationship with parents.

\section{Social Media Addiction and Relationship Quality with Parents}


Our results support those of Bilgin et al. (2020) study and suggest that social media addiction is associated with higher levels of conflict with parents. Moreover, our results go further by specifying that social media addiction is also negatively linked to positive aspects (satisfaction, equality) of the relationship with parents, especially with father. First, after controlling for important cofounding variables, social media addiction predicts a low sense of equality with both parents. This may be due to the fact that young adults who engage heavily in social media may substitute time offline with parents in favor of online interactions with peers (Mohawad \& Ebrahem, 2016). As a result, they may have fewer deep conversations with their parents, whereas these may be opportunities to demonstrate their maturity and be seen as equals to their parent's perspective. It is also possible that parents expect social media use to decrease with age, as it is known that teenagers use more social medias than adults (Schimmele et al., 2021). Thus, in the parents' view, it is possible that compulsive behaviors on social media, such as frequently scrolling during a dinner for example, are seen as a sign of immaturity. This would therefore go against the perception that their child is equal to them. Furthermore, young adults with a high social media addiction score report more conflict with both parents and less satisfaction of the relationship with the father. As seen in Markiewicz et al. (2006) study, fathers do not play a predominant role regarding the attachment of young adults. The relationship with the latter could therefore be the first to suffer when the young adult presents symptoms of behavioral addiction. Also, as social media addiction predicts satisfaction with life (Hawi \& Samaha, 2017), it is possible that young adults with addiction symptoms tend to generalize their thoughts and behaviors in several areas of their lives, including their relationship with the least close relative, namely the father (Markiewicz et al., 2006). Moreover, young adults are gaining in autonomy following the end of their mandatory school age. They are in a period of their lives where they can make more choices and depend less on their parents. This distance may 
sometimes create a feeling of lack of support from parents and makes the child compensate for this lack via social media (Boniel-Nissim \& Sasson, 2018). This would be especially applicable for fathers since they generally have a more instrumental role in their young adult's life (Finley et al., 2008).

Our results therefore support the importance of examining the relationship with the father and mother separately. In line with Bilgin et al. (2020) study, we found different direct effects of social media addiction for the relationship with the father and the mother. No associations were found between social media addiction and satisfaction of the relationship with the mother. Since mothers generally have a more expressive role with their child (i.e., fulfill caregiving and companionship functions; Finley et al., 2008), it is possible that the mother is more likely to understand the reality of their young adult. For example, mothers may be more likely not to judge their children's problematic use despite not necessarily agreeing with it. Also, young adults report more frequent contact with their mother than their father (Fingerman et al., 2012). It is therefore possible that the problematic use of social media does not directly affect the relationship with mother because of a solid communication basis.

\section{Social Media Addiction, Anxiety and Depression}

After controlling for important confounding variables, we found that social media addiction is associated with more symptoms of anxiety and depression in young adults. Recent systematic reviews observe a lack of consistency in the results of different studies, and our findings contribute to compensate for this lack (Keles et al., 2020). As previously stated, social comparison theory could explain these links (Festinger, 1954). Steers et al., (2014) found that the social comparison on Facebook predicts the level of depression in young adults. This suggests that comparing oneself with others while surfing Facebook may be the origin of the increase in internalizing symptoms, and that the direction of these comparisons, i.e. whether they are 
downward or upward comparisons, does not influence these links. Thus, symptoms of social media addiction may in fact be about the compulsive and uncontrollable need to compare oneself with others. In addition, young adults who feel emotionally connected to social media are generally people for whom their interpersonal relationships greatly define their self-esteem (Pettijohn et al., 2012). The slightest negative perception of a relationship could therefore have a great impact on well-being. Furthermore, another possible explanation is that young adults with social media addiction may be more likely to engage in attention-seeking behaviors (e.g., posting pictures of oneself), and if the expected feedback does not occur (e.g., get likes on pictures), it may create anxiety and depression (Shensa et al., 2018). Finally, our results support the idea that it is not how much time but rather how social media are used that leads to the link with mental health (Shensa et al., 2017). Examining the links between social media use and internalizing problems by considering the addiction construct is therefore clearly appropriate.

\section{Mediating Effect of Internalizing Problems}

We found evidence of a mediating effect of internalizing problems in the association between social media addiction and components of the relationship quality with both parents, although this effect may be tempered by the use of a single measurement time. On the one hand, we observed both direct and indirect effect (via internalizing problems) of social media addiction on conflict and satisfaction with the father, and conflict and equality with the mother. This may be due to the fact that those with addiction symptoms, and therefore internalizing symptoms, tend to use self-protective strategies (e.g. avoidance behavior), which impairs their ability to maintain close relationships (Tillfors et al., 2012). These avoidance behaviors may be more salient with the father since the latter generally play instrumental functions with his children (e.g., provide financial support and discipline; Finley et al., 2008). Furthermore, it seems that there is a bidirectional association between internalizing symptoms and quality of the relationship with 
parents (Branje et al., 2010; Van Eijk et al., 2012). Young adults who present symptoms of internalizing problems may induce a negative mood in the other person, and this could affect the relationship (Branje et al., 2010). Also, as peers and romantic partners play an increasing role in young adults' well-being, it is possible that young adults with addiction symptoms are more likely to share their distress with them rather than parents (Miller-Slough \& Dunsmore, 2016; Markiewicz et al., 2006). Same-age peers, including romantic partners, may be more likely to understand the implications of problematic social media use and young adults may therefore feel more understood with them rather than their parents. The distress could then increase the importance of peers and romantic partners, and decrease the importance of parents in young adults' perception.

On the other hand, we observed a full mediation for satisfaction with the mother, meaning that social media addiction did not affect directly this component of the relationship with the mother, but only via the presence of internalizing problems. Although mothers typically provide emotional support to their children (Finley et al., 2008), for those with high level of internalizing problems that is related to social media addiction symptoms, the mother may not be able to understand these issues since social media is a fairly recent phenomenon. These platforms emerged at the end of the first decade of the 2000s, having since then a significant impact in young adults' lives. Mothers in our study did not have such platforms when they were this age, so they may be less aware of their importance in the lives of their offspring and less attentive to the internalizing symptoms that their problematic use may cause. While mothers generally assume a greater role in the lives of young adults than fathers (Fingerman et al., 2012; Markiewicz et al., 2006), the lack of support from mothers among those with social media addiction may affect the relationship in a problematic way. 
We found no indirect effect of social media addiction on the sense of equality with the father. It is possible that internalizing problems is not a mechanism by which social media addiction is linked to equality with the father. Other mechanisms related to the child's success (e.g., perception of future success; Fingerman et al., 2012) may better explain the feeling of equality with the father. Indeed, social media addiction could negatively influence academic success (Giunchiglia et al., 2018) which, in turn, may influences the feeling of equality with the father by more consideration from the latter. More research on this topic is needed to clarify this association.

\section{Limitations, Strength and Practical Implication}

Our study has some limitations. First, our results should be considered with caution since they were based on correlational data collected at one single point in time. Although the proposed links have strong theoretical support, it is possible that the direction of the mediational links may be reversed, as seen in other studies with problematic internet use (i.e., the quality of the relationship with parents predicts internalizing problems which, in turn, predict social media addiction; Sela et al., 2020; Wang et al., 2018). While some studies support the validity of our single-time point mediation analysis (Cain et al., 2018), others question it due to the absence of the temporality criterion to infer a causal link. Thus, we cannot conclude on the direction of the link, but these findings open the door for other researchers to test these links longitudinally as they appear highly plausible as a result of this study. Second, all the assessments were exclusively based on young adults self-reports. In order to limit shared-method variance bias, it would be important to reproduce these results with various methods, notably for the relationship with parents where the parent's point of view could be considered. Third, young adult cohabitation with their parents should also be considered in future studies. Since almost all of the 
participants in our study were still living with at least one of their parents, a much larger sample size is needed to detect a significant effect, which prevented us from testing it.

Our study also has several strengths. First, to our knowledge, this is the first study to examine the link between social media addiction and the parent-child relationship in a sample of young adult. In doing so, we included negative and positive aspects of the quality of the relationship between young adults and their mother and father separately. The majority of similar studies are conducted in adolescence or observe the quality of the relationship as a single construct, which prevent a more detailed picture of these associations. Second, we took into account gender, parental education and family income in order to limit alternative explanations and maximize internal validity (Hair et al., 2008). Third, our study proposes a mechanism by which social media addiction can be linked to the quality of the relationship with parents. This therefore contributes to the understanding of the link. Fourth, our study is one of the first to consider the notion of social media addiction in a population of Canadian young adults.

In conclusion, the current results should encourage professionals, schools and families to be concerned about the problematic use of social media in young adults in order to prevent psychological and family problems. By being informed of the risks involved in problematic use, parents should offer support to their children and be attentive to the internalizing problems that this can potentially cause. Indeed, the symptoms of social media addiction seem to have a significant effect on the relationship between parent and child, especially with father, possibly through the undesirable effects of internalizing problems. While the literature on the link between problematic use of social media and the parent-child relationship mainly concerns adolescence, our study highlights the importance of considering the problem in young adulthood as well, since the parent plays an important role in the transition between adolescence and adulthood (Fingerman et al., 2012). 


\section{References}

Adler, T. F., \& Furman, W. (1988). A model for children's relationships and relationship dysfunctions. In S. Duck, D. F. Hay, S. E. Hobfoll, W. Ickes, \& B. M. Montgomery (Eds.), Handbook of personal relationships: Theory, research and interventions (p. 211-229). John Wiley \& Sons.

Andreassen, C. S. (2015). Online social network site addiction : A comprehensive review. Current Addiction Reports, 2(2), 175-184. https://doi.org/10.1007/s40429-015-0056-9

Andreassen, C. S., Billieux, J., Griffiths, M. D., Kuss, D. J., Demetrovics, Z., Mazzoni, E., \& Pallesen, S. (2016). The relationship between addictive use of social media and video games and symptoms of psychiatric disorders : A large-scale cross-sectional study. Psychology of Addictive Behaviors, 30(2), 252-262. https://doi.org/10.1037/adb0000160

Andreassen, C. S., Torsheim, T., Brunborg, G. S., \& Pallesen, S. (2012). Development of a Facebook addiction scale. Psychological Reports, 110(2), 501-517. https://doi.org/10.2466/02.09.18.PR0.110.2.501-517

Berryman, C., Ferguson, C. J., \& Negy, C. (2018). Social media use and mental health among young adults. Psychiatric Quarterly, 89(2), 307-314. https://doi.org/10.1007/s11126-017-9535-6

Bilgin, M., Şahin, İ., \& Togay, A. (2020). Social media addiction in adolescents and parent-adolescent

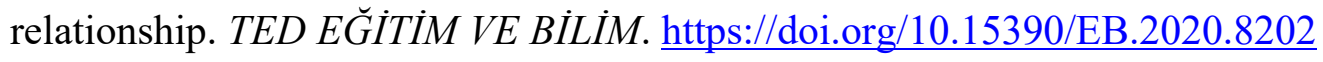

Boer, M., Stevens, G. W. J. M., Finkenauer, C., \& Eijnden, R. J. J. M. (2021). The course of problematic social media use in young adolescents : A latent class growth analysis. Child Development, cdev.13712. https://doi.org/10.1111/cdev.13712

Boniel-Nissim, M., \& Sasson, H. (2018). Bullying victimization and poor relationships with parents as risk factors of problematic internet use in adolescence. Computers in Human Behavior, 88, 176-183. https://doi.org/10.1016/j.chb.2018.05.041 
Branje, S. J. T., Hale, W. W., Frijns, T., \& Meeus, W. H. J. (2010). Longitudinal associations between perceived parent-child relationship quality and depressive symptoms in adolescence. Journal of Abnormal Child Psychology, 38(6), 751-763. https://doi.org/10.1007/s10802-010-9401-6

Bronfenbrenner, U., \& Morris, P. A. (2007). The bioecological model of human development. In Handbook of Child Psychology. John Wiley \& Sons, Ltd. https://doi.org/10.1002/9780470147658.chpsy0114

Browne, M. W., \& Cudeck, R. (1992). Alternative ways of assessing model fit. Sociological Methods \& Research, 21(2), 230-258. https://doi.org/10.1177/0049124192021002005

Cain, M. K., Zhang, Z., \& Bergeman, C. S. (2018). Time and other considerations in mediation design. Educational and Psychological Measurement, 78(6), 952-972. https://doi.org/10.1177/0013164417743003

Carr, C. T., \& Hayes, R. A. (2015). Social media : Defining, developing, and divining. Atlantic Journal of Communication, 23(1), 46-65. https://doi.org/10.1080/15456870.2015.972282

Chen, W., \& Lee, K.-H. (2013). Sharing, liking, commenting, and distressed? The pathway between Facebook interaction and psychological distress. Cyberpsychology, Behavior, and Social Networking, 16(10), 728-734. https://doi.org/10.1089/cyber.2012.0272

Côté, S. M., Orri, M., Brendgen, M., Vitaro, F., Boivin, M., Japel, C., Séguin, J. R., Geoffroy, M.-C., Rouquette, A., Falissard, B., \& Tremblay, R. E. (2017). Psychometric properties of the Mental Health and Social Inadaptation Assessment for Adolescents (MIA) in a population-based sample. International Journal of Methods in Psychiatric Research, 26(4), e1566. https://doi.org/10.1002/mpr.1566

Coyne, S. M., Rogers, A. A., Zurcher, J. D., Stockdale, L., \& Booth, M. (2020). Does time spent using social media impact mental health? : An eight year longitudinal study. Computers in Human Behavior, 104, 106160. https://doi.org/10.1016/j.chb.2019.106160 
Festinger, L. (1954). A theory of social comparison processes. Human Relations, 7(2), 117-140. https://doi.org/10.1177/001872675400700202

Fingerman, K. L., Cheng, Y.-P., Tighe, L., Birditt, K. S., \& Zarit, S. (2012). Relationships between young adults and their parents. Dans A. Booth, S. L. Brown, N. S. Landale, W. D. Manning, \& S. M. McHale (Éds.), Early Adulthood in a Family Context (p. 59-85). Springer New York. https://doi.org/10.1007/978-1-4614-1436-0_5

Finley, G. E., Mira, S. D., \& Schwartz, S. J. (2008). Perceived paternal and maternal involvement : Factor structures, mean differences, and parental roles. Fathering: A Journal of Theory, Research, and Practice about Men as Fathers, 6(1), 62-82. https://doi.org/10.3149/fth.0601.62

Furman, W., \& Buhrmester, D. (1985). Children's perceptions of the personal relationships in their social networks. Developmental Psychology, 21(6), 1016-1024. https://doi.org/10.1037/0012$\underline{1649.21 .6 .1016}$

Giunchiglia, F., Zeni, M., Gobbi, E., Bignotti, E., \& Bison, I. (2018). Mobile social media usage and academic performance. Computers in Human Behavior, 82, 177-185. https://doi.org/10.1016/j.chb.2017.12.041

Griffiths, M. (2005). A ‘components' model of addiction within a biopsychosocial framework. Journal of Substance Use, 10(4), 191-197. https://doi.org/10.1080/14659890500114359

Hair, E. C., Moore, K. A., Garrett, S. B., Ling, T., \& Cleveland, K. (2008). The continued importance of quality parent-adolescent relationships during late adolescence. Journal of Research on Adolescence, 18(1), 187-200. https://doi.org/10.1111/j.1532-7795.2008.00556.x

Hawi, N. S., \& Samaha, M. (2017). The relations among social media addiction, self-esteem, and life satisfaction in University students. Social Science Computer Review, 35(5), 576-586. https://doi.org/10.1177/0894439316660340 
Hayes, A. F. (2018). Introduction to mediation, moderation, and conditional process analysis : A regression-based approach (Second edition). Guilford Press.

Hu, L., \& Bentler, P. M. (1999). Cutoff criteria for fit indexes in covariance structure analysis : Conventional criteria versus new alternatives. Structural Equation Modeling: A Multidisciplinary Journal, 6(1), 1-55. https://doi.org/10.1080/10705519909540118

Keles, B., McCrae, N., \& Grealish, A. (2020). A systematic review : The influence of social media on depression, anxiety and psychological distress in adolescents. International Journal of Adolescence and Youth, 25(1), 79-93. https://doi.org/10.1080/02673843.2019.1590851

Kilinç, G., Harmanci, P., Yildiz, E., \& Çetin, N. (2019). Relationship between internet addiction in adolescents and family relationship : A systematic review. Journal of International Social Research, 12(67), 609-618. https://doi.org/10.17719/jisr.2019.3748

Kuss, D., \& Griffiths, M. (2017). Social networking sites and addiction : Ten lessons learned. International Journal of Environmental Research and Public Health, 14(3), 311. https://doi.org/10.3390/ijerph14030311

Lin, L. yi, Sidani, J. E., Shensa, A., Radovic, A., Miller, E., Colditz, J. B., Hoffman, B. L., Giles, L. M., \& Primack, B. A. (2016). Association between social media use and depression among U.S. young adults. Depression and Anxiety, 33(4), 323-331. https://doi.org/10.1002/da.22466

Mamun, M. A. A., \& Griffiths, M. D. (2019). The association between Facebook addiction and depression : A pilot survey study among Bangladeshi students. Psychiatry Research, 271, 628-633. https://doi.org/10.1016/j.psychres.2018.12.039

Marino, C., Gini, G., Vieno, A., \& Spada, M. M. (2018). The associations between problematic Facebook use, psychological distress and well-being among adolescents and young adults : A systematic review and meta-analysis. Journal of Affective Disorders, 226, 274-281. https://doi.org/10.1016/j.jad.2017.10.007 
Markiewicz, D., Lawford, H., Doyle, A. B., \& Haggart, N. (2006). Developmental differences in adolescents' and young adults' use of mothers, fathers, best friends, and romantic partners to fulfill attachment needs. Journal of Youth and Adolescence, 35(1), 121-134. https://doi.org/10.1007/s10964-005-9014-5

Miller-Slough, R. L., \& Dunsmore, J. C. (2016). Parent and friend emotion socialization in adolescence : Associations with psychological adjustment. Adolescent Research Review, 1(4), 287-305. https://doi.org/10.1007/s40894-016-0026-Z

Moawad, G. E. N. A., \& Ebrahem, G. G. S. (2016). The relationship between use of technology and parent-adolescents social relationship. Journal of Education and Practice, 7(14), 168-178.

Muthén, L.K. and Muthén, B.O. (1998-2015). Mplus User's Guide. Seventh Edition. Los Angeles, CA: Muthén \& Muthén

Pettijohn II, T. F., LaPiene, K. E., Pettijohn, T. F., \& Horting, A. L. (2012). Relationships between Facebook intensity, friendship contingent self-esteem, and personality in U.S. College Students. Cyberpsychology: Journal of Psychosocial Research on Cyberspace, 6(1). https://doi.org/10.5817/CP2012-1-2

Pew Research Center (2019) : social media fact sheet. Retrieved on https://www.pewresearch.org/internet/fact-sheet/social-media/

Poulin, F., Capuano, F., Vitaro, F., Verlaan, P., Brodeur, M., \& Giroux, J. (2013). Large-scale dissemination of an evidence-based prevention program for at-risk kindergartners: Lessons learned from an effectiveness trial of the Fluppy Program. In M. Boivin \& K.L. Bierman (Eds.), Promoting school readiness: The Implications of developmental research for practice and policy (pp. 304-328). Guilford Press.

Rideout, V., and Robb, M. B. (2019). The Common Sense census: Media use by tweens and teens, 2019. San Francisco, CA: Common Sense Media. 
Sampasa-Kanyinga, H., Goldfield, G. S., Kingsbury, M., Clayborne, Z., \& Colman, I. (2020). Social media use and parent-child relationship : A cross-sectional study of adolescents. Journal of Community Psychology, 48(3), 793-803. https://doi.org/10.1002/jcop.22293

Sela, Y., Zach, M., Amichay-Hamburger, Y., Mishali, M., \& Omer, H. (2020). Family environment and problematic internet use among adolescents : The mediating roles of depression and Fear of Missing Out. Computers in Human Behavior, 106, 106226. https://doi.org/10.1016/j.chb.2019.106226

Shensa, A., Escobar-Viera, C. G., Sidani, J. E., Bowman, N. D., Marshal, M. P., \& Primack, B. A. (2017). Problematic social media use and depressive symptoms among U.S. young adults : A nationally-representative study. Social Science \& Medicine, 182, 150-157. https://doi.org/10.1016/j.socscimed.2017.03.061

Shensa, A., Sidani, J. E., Dew, M. A., Escobar-Viera, C. G., \& Primack, B. A. (2018). Social media use and depression and anxiety symptoms : A cluster analysis. American Journal of Health Behavior, 42(2), 116-128. https://doi.org/10.5993/AJHB.42.2.11

Schimmele, C., Fonberg, J., \& Schellenberg, G. (2021). Canadians' assessments of social media in their lives. Economic and Social Reports, 1(3). Statistics Canada. https://doi.org/10.25318/36280001202100300004-eng

Stavropoulos, V., Motti-Stefanidi, F., \& Griffiths, M. D. (2021). Risks and ppportunities for youth in the digital era. European Psychologist. https://doi.org/10.1027/1016-9040/a000451

Steers, M.-L. N., Wickham, R. E., \& Acitelli, L. K. (2014). Seeing everyone else's highlight reels : How Facebook usage is linked to depressive symptoms. Journal of Social and Clinical Psychology, 33(8), 701-731. https://doi.org/10.1521/jscp.2014.33.8.701 
Tanner, J. L., \& Arnett, J. J. (2016). The emergence of emerging adulthood: The new life stage between adolescence and young adulthood. Dans Routledge Handbook of Youth and Young Adulthood (2e éd., p. 7). Routledge.

Tillfors, M., Persson, S., Willén, M., \& Burk, W. J. (2012). Prospective links between social anxiety and adolescent peer relations. Journal of Adolescence, 35(5), 1255-1263. https://doi.org/10.1016/j.adolescence.2012.04.008

Van Eijck, F. E. A. M., Branje, S. J. T., Hale, W. W., \& Meeus, W. H. J. (2012). Longitudinal associations between perceived parent-adolescent attachment relationship quality and generalized anxiety disorder symptoms in adolescence. Journal of Abnormal Child Psychology, 40(6), 871-883. https://doi.org/10.1007/s10802-012-9613-z

Vannucci, A., Flannery, K. M., \& Ohannessian, C. M. (2017). Social media use and anxiety in emerging adults. Journal of Affective Disorders, 207, 163-166.

https://doi.org/10.1016/j.jad.2016.08.040

Wang, W., Li, D., Li, X., Wang, Y., Sun, W., Zhao, L., \& Qiu, L. (2018). Parent-adolescent relationship and adolescent internet addiction : A moderated mediation model. Addictive Behaviors, 84, 171-177. https://doi.org/10.1016/j.addbeh.2018.04.015

Yap, M. B. H., Pilkington, P. D., Ryan, S. M., \& Jorm, A. F. (2014). Parental factors associated with depression and anxiety in young people : A systematic review and meta-analysis. Journal of Affective Disorders, 156, 8-23. https://doi.org/10.1016/j.jad.2013.11.007 
Table 1

Tables

Descriptive statistics and bivariate correlations

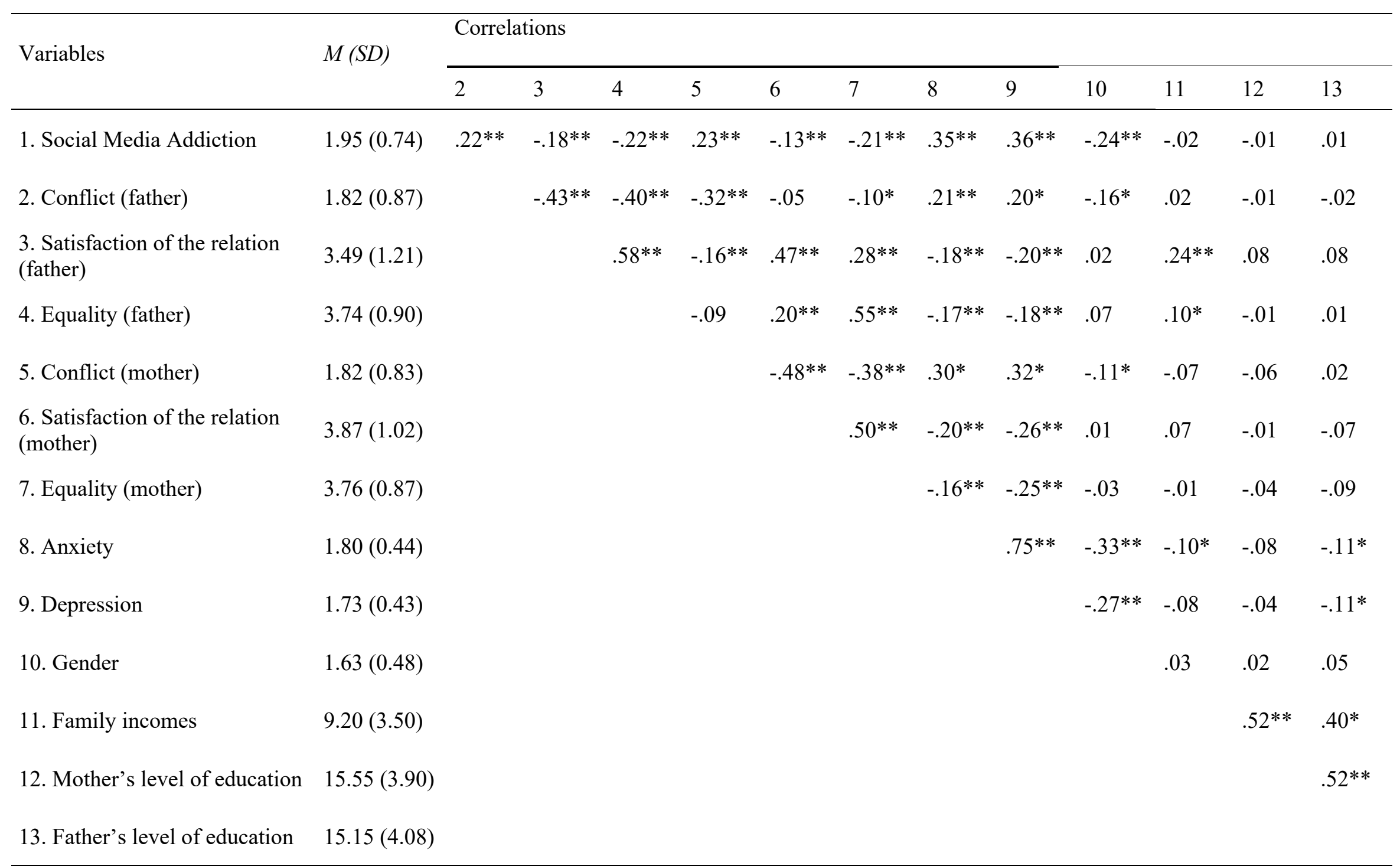

Note. Gender is coded as 1 (females) and 2 (males), whereas $63 \%$ of the participants are males.

$* *=p<0.01$ (two-tailed)

$*=p<0.05$ (two-tailed) 
Table 2

Path Analysis Results

\begin{tabular}{lcccc}
\hline & $\beta$ & SE & $p$ & $95 \%$ CI $(\beta)$ \\
\hline On social media addiction & & & & \\
\hline Internalizing problems & $.36^{*}$ & .05 & .00 & $.27, .44$ \\
Conflict (father) & $.15^{*}$ & .05 & .01 & $.04, .25$ \\
Satisfaction (father) & $-.14^{*}$ & .05 & .01 & $-.25,-.04$ \\
Equality (father) & $-.17^{*}$ & .05 & .00 & $-.27,-.07$ \\
Conflict (mother) & .10 & .05 & .04 & $.00, .20$ \\
Satisfaction (mother) & -.03 & .05 & .51 & $-.14, .07$ \\
Equality (mother) & $-.15^{*}$ & .05 & .00 & $-.25,-.05$ \\
\hline On internalizing problems & & & & \\
\hline Conflict (father) & $.18^{*}$ & .06 & .00 & $.06, .30$ \\
Satisfaction (father) & $-.18^{*}$ & .06 & .00 & $-.29,-.06$ \\
Equality (father) & $-.14^{*}$ & .06 & .02 & $-.26,-.02$ \\
Conflict (mother) & $.32^{*}$ & .06 & .00 & $.21, .43$ \\
Satisfaction (mother) & $-.28^{*}$ & .06 & .00 & $-. .40,-.17$ \\
Equality (mother) & $-.23^{*}$ & .06 & .00 & $-.34,-.11$ \\
\hline
\end{tabular}

Indirect effect of social media addiction via internalizing

problems

$\begin{array}{llllc}\text { Conflict (father) } & .06^{*} & - & - & .01, .12 \\ \text { Satisfaction (father) } & -.06^{*} & - & - & -.11,-.01 \\ \text { Equality (father) } & -.05 & - & - & -.10, .00 \\ \text { Conflict (mother) } & .11^{*} & - & - & .06, .16 \\ \text { Satisfaction (mother) } & -.10^{*} & - & - & -.15,-.05 \\ \text { Equality (mother) } & -.08^{*} & - & - & -.13,-.03\end{array}$

$* p<.05$

Note. Bold characters indicate predictors. Covariates are family incomes, gender and parents' level of education. 
Figure 1

Illustration of the structural equation model

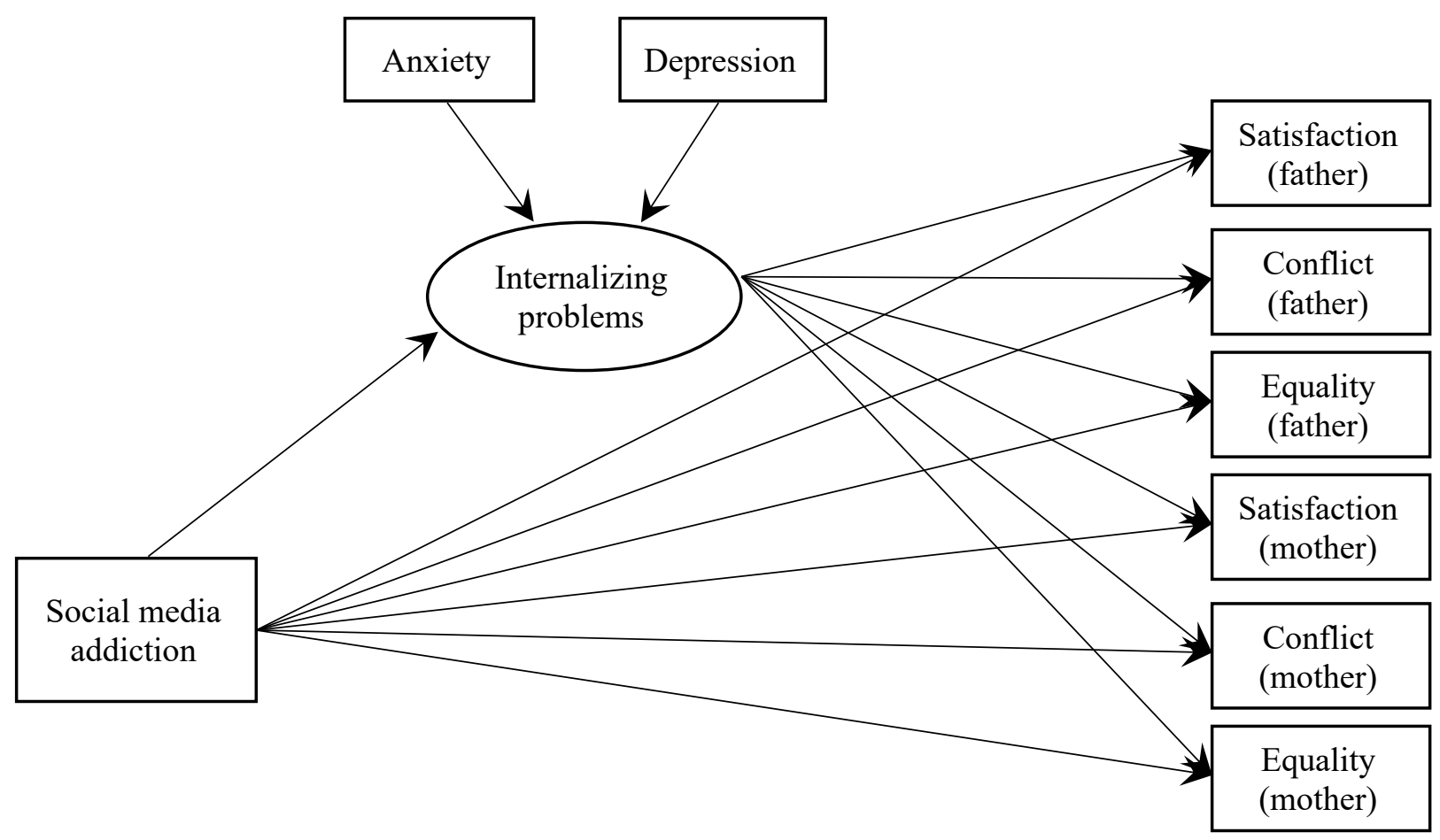

